
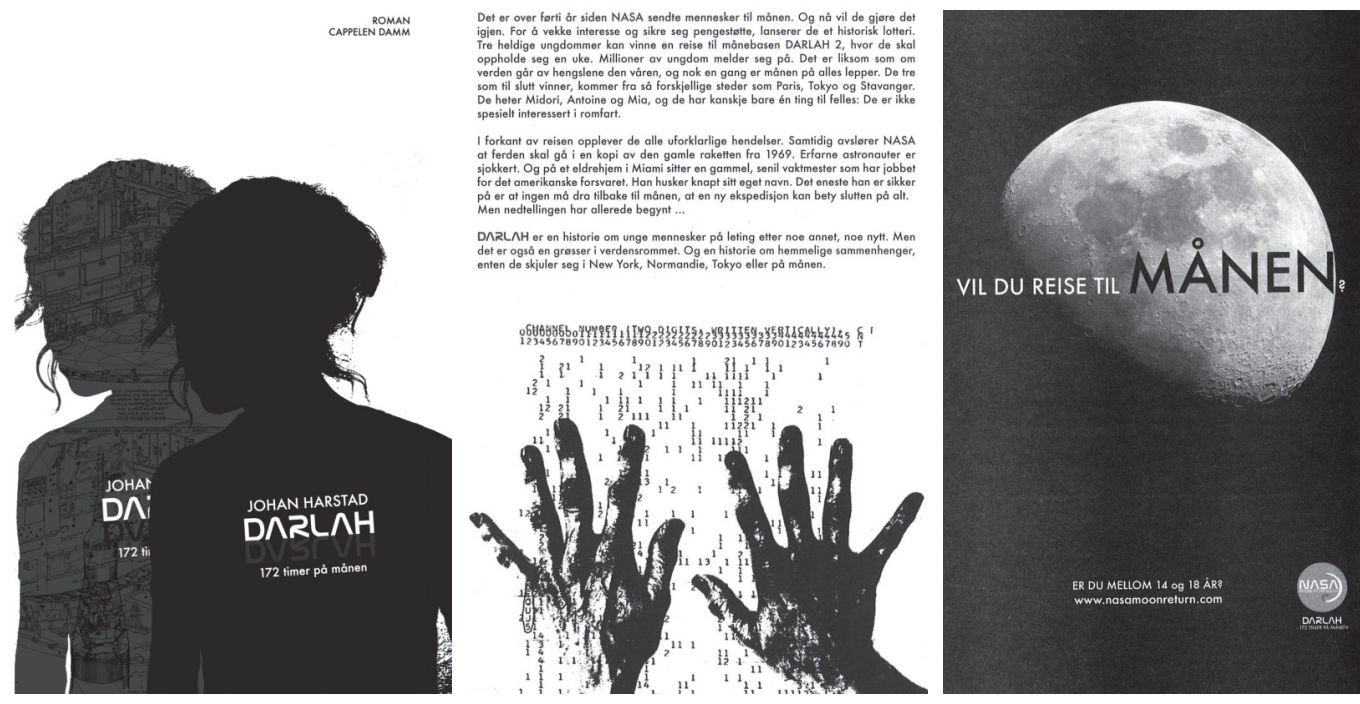

Kjersti Lersbryggen Mørk

\title{
Terror i tvillingtårnene - dystopi og ironi? 9/II i Darlah og En terrorist i senga
}

http://urn.kb.se/resolve?urn=urn:nbn:se:sbi-36

Citation: Nordic Journal of ChildLit Aesthetics, Vol. 2, 2011 DOI: 10.3402/ blft.v2i0.5839

Abstract: Terror in the Twin Towers - dystopia and irony? 9/11 in Darlah and En terrorist i senga. Through globalization of our media society, children as well as adults are endlessly exposed to information and images from all over the world. In Norway, signs of the terrorist attack on the Twin Towers in USA on September $11^{\text {th }} 2001$ are now to be found in literature for children and young adults. With globalization theory and post-colonial theory I will examine how two novels present global challenges in general and 9/11 in particular. What does globalization mean for the construction of identity? Who are "we", and who are "the others"? The novel for young adults, Darlah - 172 timer på månen [Darlah - 172 hours on the moon] (2008) by Johan Harstad, is a dystopia where 9/11 points forward to a full scale catastrophe for humanity. En terrorist i senga [There's a terrorist in 


\section{The Alew Hork Eimes}

DARLAH Capsule Recovered - Sole Survivor Found
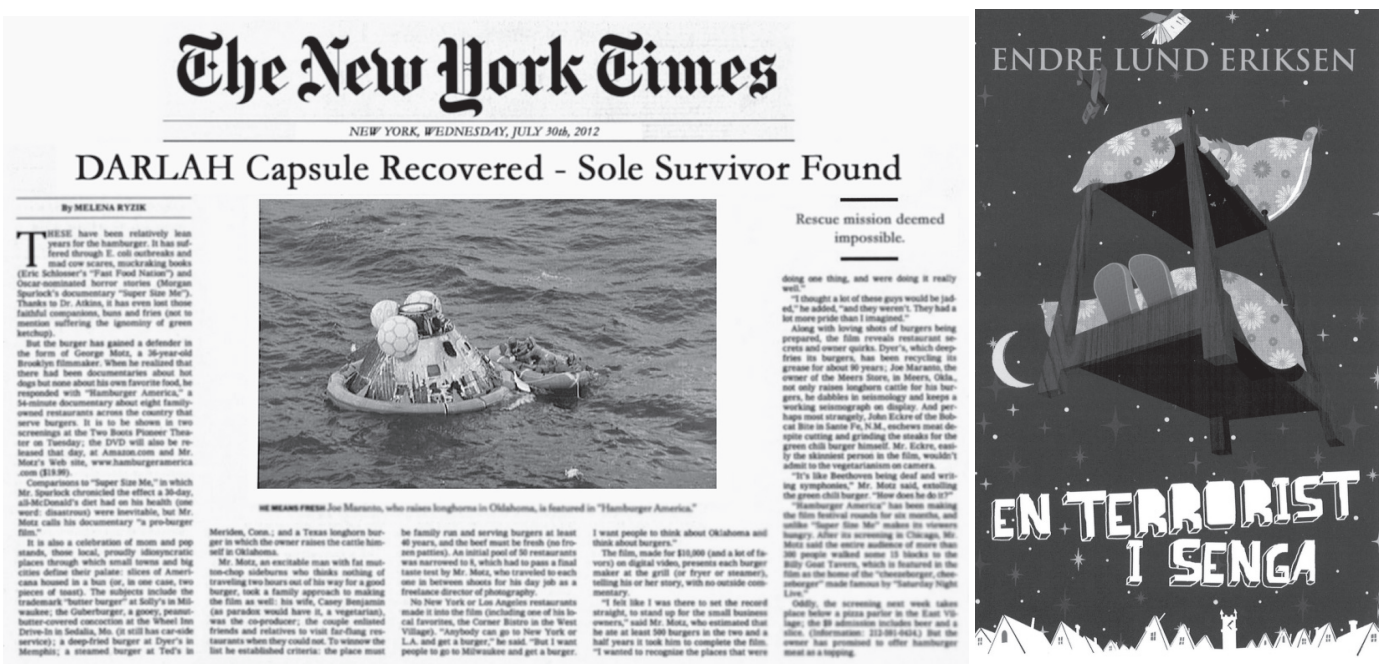

my bed] (2008), a novel for children by Endre Lund Eriksen, makes explicit references to 9/11 - but with playfulness and ironic revelation of xenophobia. Both books use aliens from outer space as "the other", but where Darlah presents a pessimistic view of our global future, En terrorist i senga is optimistic on behalf of the humankind.

Keywords: globalization, identity, national, apocalypse, xenophobia, humour, Norwegian children's literature, Johan Harstad, Endre Lund Eriksen

Barn som voksne eksponeres for globaliseringens grensesprengende informasjonsflyt - også når det er trøbbel i tårnet. Signaler fra 9/11 finnes nå i norsk barnelitteratur. Tradisjonelt har denne litteraturen hatt fokus på en barnlig protagonist i et hjemlig miljø på den norske landsbygda, med skog, fjell og fjorder som naturlige rammer for barnlig utfoldelse. På begynnelsen av 1900-tallet var barnelitteraturen en viktig del av oppbyggingen av den nasjonale identitetsfølelsen etter de dunkle hundreårene under dansk og svensk styre. Når tvillingtårnene nå kaster skygger inn i norsk barnelitteratur, er det interessant fordi fenomenet utfordrer så vel det hjemlige fokuset som en tradisjonell oppfattelse av barnevennlige tema i litteraturen.

Dagens norske kollektive identitet er i mindre grad en stabil størrelse. Nasjonale identiteter er under stadig forhandling i vår globaliserte tid. Homi K. Bhabha, professor i engelsk litteratur, er opptatt av at kultur og identitet er hybride, flytende og forestilte fenomener under stadig forhandling, mens nasjonsforestillinger har lett for å 
stivne og virke ekskluderende (Huddart 2006, 6). Kristin Ørjasæter, norsk litteraturforsker, hevder at vår tids barnelitteratur utøver "en form for nasjonalismekritikk, der nasjonale symboler blir betraktet som klisjeer" $(2010,59)$. Australske Jo Lampert har skrevet en doktoravhandling om 9/11 i hovedsakelig amerikansk barnelitteratur. Hun har undersøkt hvordan identitet framstilles i denne litteraturen, og identitetskategoriene etnisk, nasjonal og heroisk framstår som særlig signifikante: "In these three identities come an image of a post-9/11 world where producing the right kind of person for the good of the nation is privileged over ideas of absolute tolerance." (Lampert 2010, 175) Global harmoni og kulturell toleranse er underordnet nasjonal lojalitet i Lamperts materiale.

Det kan synes som om amerikansk og norsk barnelitteratur beveger seg i hver sin retning hva gjelder problemstillingen global vs. nasjonal. Med globaliseringsteori og postkolonial teori vil jeg se nærmere på norsk barnelitteratur som presenterer globale utfordringer generelt og 9/11 spesielt. Hva betyr globalisering for konstruksjonen av identitet? Dersom nasjonal identitet handler om å markere grenser mot verden - hvordan posisjonerer barnelitteraturen seg i forhold til etablerte nasjonsforestillinger? Hvem framstilles som "vi" og "de andre"?

Globalisering handler om økt og mer kompleks interaksjon på tvers av kulturelle og geografiske grenser. Reiser, migrasjon og elektroniske medier er viktige dimensjoner ved kulturell globalisering. John Tomlinson, britisk professor i kulturstudier, sier at globaliseringen svekker båndene mellom kultur og sted - et fenomen han kaller "deterritorialization":

[...] a central defining characteristic of deterritorialization is the weakening or dissolution of the connection between everyday lived culture and territorial location. However this is not typically experienced as simply cultural loss or estrangement but as a complex and ambiguous blend: of familiarity and difference, expansion of cultural horizons and increased perceptions of vulnerability, access to the "world out there" accompanied by penetration of our own private worlds, new opportunities and new risks (Tomlinson 1999, 128).

I dag har globaliseringens "new opportunities and new risks" implikasjoner for litteraturen som overskrider det norske og nordiske. Verden er i økende grad tilgjengelig gjennom reelle og virtuelle erfaringer. Samtidig foregår en motsatt bevegelse, en reterritorialisering, 
der det lokale får fornyet fokus. Forholdet mellom sted og kultur kan aldri bli helt vilkårlig da menneskets identitet er kroppslig og som oftest stedlig forankret. Globaliseringen innebærer altså både en overskridelse av og en fokusering på det lokale. Spørsmålet er hvordan dette påvirker litteraturens innhold og form.

Nettopp globaliseringens innvirkning på barne- og ungdomslitteraturen er ett av temaene i bøkene Radical children's literature: future visions and aesthetic transformations in juvenile fiction av den britiske professoren Kimberley Reynolds, og New world orders in contemporary children's literature: utopian transformations av de australske forskerne Clare Bradford, Kerry Mallan, John Stephens og Robyn McCallum. Begge bøkene viser hvordan terror, blant flere globale utfordringer, reflekteres i tekster for barn og unge. Forfatterne understreker imidlertid at barne- og ungdomslitteraturen, også den dystopiske, som regel skaper visjoner om en bedre verden.

Utgangspunktet for postkolonial teori er at vestlig modernitet og framskritt er basert på kolonialismens undertrykkelse og utbytting. I Orientalism (1978) argumenterer den palestinsk-amerikanske litteraturprofessoren Edward Said for at Vesten har skapt et bilde av Orienten som sin definerende kontrast: irrasjonelt, eksotisk, despotisk. Kolonial makt forsøker å etablere en stabil og endelig avgrensing mellom koloniherre og den koloniserte som aldri kan realiseres. Kolonialismen deler verden inn i "vi" og "de andre", der stereotypier og fordommer legitimerer over- og underordning.

Hvilke visjoner og endringsmuligheter ligger i skildringene av globale og postkoloniale utfordringer i den norske barnelitteraturen? Ungdomsromanen Darlah - 172 timer på månen av Johan Harstad og barneromanen En terrorist $i$ senga av Endre Lund Eriksen synes å representere to ulike måter å forholde seg til globaliseringen og terroren i tvillingtårnene. Jeg vil argumentere for at Darlah forholder seg dystopisk, i betydningen framtidspessimistisk, mens En terrorist $i$ senga bruker ironi og humor i møte med globale utfordringer.

\section{Darlah - 172 timer på månen av Johan Harstad}

Johan Harstad skriver noveller, romaner og skuespill, hovedsakelig for voksne. I 2001 debuterte han med korttekstsamlinga Herfra blir du bare eldre. Darlah er hans første bok for ungdom, der han gjennom kunstprosjektet/organisasjonen The Lacktr Prpgnda Community også står bak bokas omslag og en rekke av illustrasjonene. Lacktr blander fakta og fiksjon i sin produksjon av grafikk, lyd, film, foto og tekst. Darlah vant Brageprisen i 2008. 
I Darlah - 172 timer på månen har en gruppe mektige amerikanske menn bestemt at NASA igjen skal reise til månen. For å skape PR og penger lanseres et lotteri for ungdom der premien er en billett til månen. Blant millioner av håpefulle er vinnerne Antoine fra Paris, Midori fra Tokyo og Mia fra Stavanger. Alle tre opplever foruroligende hendelser i forkant av reisen, og på månen møter mannskapet aliens, i form av sine egne dobbeltgjengere, som dreper hele ekspedisjonen. Bare Mia synes å unnslippe, men når hun ankommer jorda er det åpenbart hennes dobbeltgjenger som kopierer og dreper mennesker i et rasende tempo. Til slutt er jorda nærmest fri for menneskelig eksistens.

Darlah kan leses som en dystopi, der en rekke motiver peker apokalyptisk mot verdens undergang. 9/11 er i så måte et sentralt frampek. For Mias del sammenlignes vinnerloddet til månen med en armert atombombe. Som vokalist og gitarist får Mia utløp for denne spenningen gjennom framføringen av sangen "II", en tekst hun skrev inspirert av de ti år gamle TV-bildene av terrorangrepet på tvillingtårnene. Mens stengene ryker brøler Mia refrenget: "And office has to be re-installed". En øredøvende stillhet følger bandets utblåsning: "Det var som om lyden sank mot gulvet som papiret hadde gjort den gang tvillingtårnene falt." (85) Månereisen knyttes til 9/11, atomkrig og stillhet, og ved bokas slutt er stillheten og verdens undergang nærmest total. Menneskeheten er nesten utslettet og kan bli vanskelig å gjeninnsette. Dermed blir $9 / 11$ et symbol både på det globale budskaps påvirkningskraft og på menneskelig destruksjon og sårbarhet.

Foruten datohenvisningen har "II" et visuelt aspekt som kan markere to tårn. Det visuelle er for øvrig tildelt en større plass i Darlah enn tradisjonelt i ungdomsbøker. Over 20 fotografier og grafiske plansjer er gjengitt i boka. 9/11 formidles således også gjennom et foto som viser papir og støv i gatene i etterkant av angrepet på tvillingtårnene. Slik forankres fiksjonen gjennom skrift og bilde i tid og rom. Tradisjonelt har fotografiet hatt høy troverdighet som dokumentasjon av en faktisk virkelighet. Med dagens muligheter for elektronisk manipulering og sømløse endringer er imidlertid fotografiets stilling som formidler av objektiv virkelighet betydelig svekket. Et eksempel på blanding av det dokumentariske og det fiktive er et foto av det hypermedierte stedet Shibuya crossing, i Tokyos shopping- og underholdningsdistrikt, der den fiktive NASAreklamen for månelotteriet er montert inn på enorme videoskjermer. Grensene mellom virkelighet og fiksjon tilsløres, noe som forsterker bokas uro og skrekk. 
Medienes enorme makt tematiseres i Darlah. NASAs globale mediestrategi synes svært vellykket, der månelotteriet kringkastes verden over i konvensjonelle og elektroniske medier. "Ordet NASA var på vei til å bli like velkjent som Coca Cola og McDonald's." (21) Amerikanske interesser dominerer den globale informasjonsflyten, noe som også gjenspeiles i hvordan USAs president taler på tv om måneekspedisjonen i "fremtidsoptimismens tegn". Ekspedisjonen, som direktesendes til den vestlige verden, rammes imidlertid av blind tro på mediet og dets mektige menn når presidenten erklærer offentlig minnestund for et høyst levende mannskap, fordi radiokontakten med månen er brutt.

Romanens hovedpersoner er tre unge verdensborgere - riktignok med et solid vestlig tyngdepunkt. Forskjellen mellom de tre unge menneskene er i utgangspunktet åpenbar. Musikk er en viktig identitetsmarkør for Mia. Hun gjør sitt beste for å bli forelsket i Talking Heads - deres kalde, elektroniske 80-tallssound ville etter all sannsynlighet kle hennes punkrockimage - og markere avstand til jevnaldrende og deres "tyggegummipop". Det voksne etablissement har hun bare ironi til overs for, som tittelen på hennes nyeste låt, "Bomb Hiroshima Again", gjenspeiler. For Midori er New York friheten og fienden "den japanske fellen" i betydningen ekteskap. Gatemote er hennes måte å markere individualitet og samtidig tilhørighet til det fargerike ungdomsmiljøet i Harajuku. Antoine er fascinert av flytrafikkens logistikk, og på rommet sitt har han en enorm modell av bombeflyet B-52. Riktignok inneholder ikke modellen annet enn sigaretter, som kun har begrenset effekt på hans voldsomme kjærlighetssorg. Fellesmenneskelige behov for anerkjennelse og frihet forbinder imidlertid de tre ungdommene, samtidig som kulturelle forskjeller nedtones og geografiske avstander overvinnes i møtet med et felles, utenomjordisk prosjekt.

Det lokale og nasjonale hører med i det globale bildet i Darlah. De tre hovedpersonenes hjembyer blir skildret med særtrekk som blir motiv for å søke ut i verden. Mias Stavanger er strand og by, autoritære lærere og sære bussjåfører. For Antoine er Paris en parodi på kjærlighetens by, der Eiffeltårnets kikkerter brukes til å spionere på eks-kjæresten. I Midoris Tokyo er kjøpesenteret Shibuya 109 et viktig sentrum, med horder av folk og klamme prøverom. I møtet med månens ukjente, frysetørrete meny fra 70-tallet søker imidlertid proamerikanske Midori det trygge og hjemlige: "Men da forventer jeg at dere har lagret noe asiatisk mat her også, ikke bare en haug med hamburgere" (217). Uansett ambivalens knyttet til deres lokale forankring, gjør møtet med månen at ungdommene erkjenner jordkloden som sitt 
hjem. Metaforene som brukes på månen endrer karakter fra NASAs visjon om "Disneyland", Midoris parallellføring med Robinsons "øde øy", til møtet med en livløs "ørken" før kulminasjonen av månebasen som et gudsforlatt "skrekkabinett".

Den onde andre er i Darlah menneskets dobbeltgjenger. En kryptisk kraft identifisert som 6EQUJ5 og NOWONMAI truer mannskapet på månen: "DERE KOMMER IKKE TIL Å OVERLEVE". NOWONMAI lest baklengs blir "I am no one", og ytterligere identifisering synes umulig ettersom kraften kun opptrer som kopier av mannskapet. For øvrig kan NOWONMAI knyttes til romanen The Exorcist (Blatty, 1971, filmen med samme navn kom i 1973, regissert av William Friedkin) og et amerikanske post-rock-album Nowonmai fra 2005 av bandet The Timeout Drawer. Fiksjonen skaper et intrikat spill av skriftlige og billedmessige referanser til virkeligheten så vel som til andre fiksjoner. Darlahs form tematiserer en post-strukturalistisk meningsutsettelse, noe som også gjenspeiles i romanens portrett av det onde. Det etableres et "vi" mennesker mot "de" dobbeltgjengerne, som verken består av kjøtt, blod eller moralske anfektelser. Lest utifra Freuds The uncanny, kan man si at dobbeltgjengerne inkarnerer menneskehetens fortrengte erfaringer, en demonisering av det fremmede der 9/11 utgjør et illevarslende omen. Vesensskille eller ikke - når fienden er skapt i menneskets bilde blir det vanskelig å identifisere denne. Jordklodens mennesker kan fortrenges fordi den onde kraften unndrar seg en egen definert identitet. Mennesket blir et medium for sin egen tilintetgjørelse. Det globale budskap spres med en effektivitet elektroniske medier ville, hvis de kunne, drømme om.

Etterordet "Shibuya 2015" er et brev fra det siste gjenlevende mennesket i Tokyo. Den menneskeskapte verden er lagt i ruiner, men er i ferd med å gjenerobres av naturen - ikke så ulikt Talking Heads låt "(Nothing but) Flowers", som Mia lytter til på månen: "There was a shopping mall. Now it's all covered with flowers". Verdens undergang er også temaet i bildet som er gjengitt på Darlahs siste side, som forestiller et post-apokalyptisk Shibuya. Bildet, som presenteres som en tegning av det siste mennesket, er et litografi av den japanske kunstneren Hisaharu Motoda. Verket "Revelation-Electric City" (2004) er en del av litografiserien Neo-Ruins der naturen "overmanner" kulturen. Et futuristisk innhold møter litografiets eldre form, som åpner for perspektiver på fortid og framtid, fiksjon og virkelighet.

Darlahs avslutning kan leses som en understreking av den buddhistiske sannheten alt er forgjengelig. Fraværet av menneskelig 
eksistens betyr befrielse fra gjenfødelse, i det minste i menneskelig form, men det er tvilsomt om en utdøende menneskehet kvalifiserer til det ultimate nivå av nirvana. Post-apokalyptiske trekk, mer eller mindre religiøse, gjenfinnes også i japansk populærkultur. En rekke japanske endetidsfortellinger i ulike medier har dessuten settinger som er modellert etter det virkelig Shibuya. Et Nintendo DS-spill fra Shibuya-distriktet har den megetsigende tittelen "The world ends with you", mens TV-serien "Sh15uya" utspiller seg ved shoppingsenteret Shibuya 109 og dets imaginære tvillingtårn, 108, der en klokke teller ned mot verdens undergang jamfør de amerikanske tvillingtårnenes apokalyptiske funksjon. Modernitet, framskritt, teknologi, globalisering blir menneskets bane - mens kloden rykker tilbake til start.

\section{En terrorist i senga av Endre Lund Eriksen}

Endre Lund Eriksen skriver romaner og filmmanus, der barnebøker utgjør majoriteten av hans produksjon. Han debuterte med barneboka Pitbull-Terje går amok i 2002. En terrorist $i$ senga ble i 2008 stemt fram av barn i 5.-7. klasse som vinner av ARKs barnebokpris.

Som i Darlah spiller utenomjordisk liv en sentral rolle i En terrorist $i$ senga. 11-åringen Adrian finner en bevisstløs, mørkhudet ungdom i snøen, som uten et forståelig språk og uten hukommelse ikke har noen mulighet til å gjøre rede for seg. Adrian kaller ham Ali og holder ham skjult på rommet sitt, gjemt i underkøya. På bakgrunn av Alis gylne hud og mørke hår er Adrian overbevist om at Ali er muslim, og for å bidra til identitetsoppklaringen iverksetter Adrian en rekke tiltak av typen håndkle på hodet og bønn mot Mekka på et leketeppe. Ali reagerer med latter - og ikke gjenkjennelse. Motvillig ber Adrian om hjelp fra ei jente og klassens muslim, Marjaneh, for å bringe klarhet i Alis mulige muslimske identitet. Under lek avslører imidlertid Ali en bemerkelsesverdig kjennskap til fly, noe som bekymrer Adrian nok til å ringe inn et tips om en ulovlig flyktning. Paradoksalt nok er det Adrians fremmedfiendtlige oldefar, sammen med Marjaneh og den angrende angiveren Adrian, som hjelper Ali med å flykte fra politi og militære styrker. Under flukten gjenvinner Ali hukommelsen om sin utenomjordiske opprinnelse, leter opp romskipet sitt, og setter kurs ut i verdensrommet. På julaften kommer han imidlertid tilbake til Adrian.

Allerede i tittelen henviser En terrorist $i$ senga til terror, og 9/11 er en sentral referanse gjennom hele boka. Temaet knyttes til lek. I utgangspunktet er jeg-fortelleren Adrians tilnærming til den 
fremmede unggutten preget av det vestlige, medieskapte fiendebildet av islam. Til tross for et tilsynelatende tolerant og veslevoksent resonnement, avslører Adrian en "mørkeredsel": "Det var ingen grunn til å være redd han. Det er veldig mange folk som er muslimer. Bare noen veldig få av dem er terrorister. Men jeg lot lyset være på. Av praktiske grunner." (21) Adrian setter også et navn på unggutten - Ali - og definerer ham dermed som en fremmed, som alien. Ali kan også leses som en arabiskklingende merkelapp med mulige konnotasjoner til Al-Qaida. Den lokale militære flyplassen har høynet sin beredskap som følge av "krigen mot terror", men det er Adrians oldefar som først eksplisitt målbærer terrorfrykten, idet han med direkte henvisning til 9/11 finner Alis interesse for fly svært urovekkende. Når Alis overjordiske flyferdigheter viser seg å skyldes hans utenomjordiske bakgrunn, avsløres fordommene som feilaktige stereotypier. Med humor og ironi utfordres det skarpe skillet mellom øst og vest som 9/11 her er et symbol på. Den avsluttende gjenforeningsscenen mellom Ali og Adrian bærer også preg av et lekent og avvæpnende forhold til det alvorstunge symbolet, med gjensynsglede i fokus: "Som et fly føyk jeg rett mot han, krasja i han og brøyt han over ende, mens jeg lagde eksplosjonslyder. Ali brøyt tilbake og sprakte sprenglyder." (246)

Adrian søker å fastholde en identitet som en aftenbønnskristen gutt med barmhjertighet for et fremmed, hjelpeløst menneske i et kaldt, norsk klima. Som bistandsyter tar Adrian på seg retten og plikten til å definere den hjelpetrengendes identitet. Med en velmenende, men likevel nedlatende norsk selvgodhet bidrar Adrian til opprettholdelse av skillet mellom "vi" og "de andre": "Det er viktig å være veldig hyggelig mot våre nye landsmenn. Så skjønner de med en gang at folk er mye greiere her enn i landet de dro fra." (24) Adrian mener å vite at Afghanistan et fattig land med mange terrorister, mens nordmenn løser konflikter ved å ta hverandre i hendene. Slik holder Adrian fast ved forestillingen om Norge som fredsnasjon, en kollektiv identitetsforståelse det har blitt stilt spørsmål ved i forbindelse med norske styrkers tilstedeværelse i nettopp Afghanistan.

Oldefar er langt mer direkte fremmedfiendtlig enn sitt oldebarn. For 81-åringen er innvandrere synonymt med "svartinger", tyver og folk på trygd. Når Adrian påpeker at oldefar selv er trygdet, avviser han parallellen ved å betone fellesskapet med "vi som har overlevd krigen, og bygd landet stein for stein" (16) Oldefar avkles også gjennom sin ytre framtoning, subbende rundt i ullundertøyet med et ansikt der "dødninghodet" blir alt mer tydelig. Med humor blir det rasistiske skrømtet mindre farlig, selv om Adrian tar visse 
forhåndsregler når Ali skal be og vender bønneteppet vekk fra oldefar. Humoren rammer ikke kun oldefars fordommer - også Adrians måte å påtvinge den andre sin egen forståelse av dennes identitet, herunder religionsutøvelse, avsløres.

Å finne ut av Alis sanne identitet er et hovedanliggende for Adrian - tilsynelatende. Med sin outsiderposisjon i forhold til klassens guttegjeng, har Adrian behov for å holde Ali i skjul som sitt eksotiske og eksklusive leketøy. Adrian trekker inn Marjaneh for å få bekreftet Alis identitet, men det er hans egne forestillinger om muslimer som blir satt på prøve. Det overrasker Adrian at hjemmet til Marjaneh er "helt normalt" med elg $i$ solnedgang, panel på veggene og plakater av Britney Spears. Men det er først når Marjaneh påpeker likheten mellom henne og Adrian - at de er skoleflinke, misliker gym og har få venner - at den upålitelige jeg-fortellerens oppdeling i "vi" og "de andre" torpederes. Når Ali glir rett inn i guttegjengen, forsøker Adrian fortvilet å fastholde "vi" norske gutter mot "de" innvandrerne:"Jeg holdt øye med dem fra skogen. Så ikke noen skulle være ekle mot Ali. Han var jo innvandrer." (140) Når skillet mellom "vi" og "de andre" blir utydelig, skaper dette et angstfylt behov hos Adrian for å opprettholde stereotypiene som legitimerer maktbruk og forskjellsbehandling. Adrian har et eiendomsforhold til gutten han har gitt navnet Ali, og når dette forholdet utfordres, ringer Adrian inn et anonymt tips om en ulovlig flyktning i Multebærveien 1.

Tradisjonelle norske identitetsmarkører blir viktige for Adrian og oldefar i møtet med det fremmede. Alis flyentusiasme blir så bekymringsverdig at bønnematta byttes ut med Fadervår, brunost og Kardemomme by. Den norske kulturen målbæres gjennom Adrians selvironiske blikk når Ali og oldefar gir seg hen til Norges nasjonalsport; langrennsløp på tv "Heia Norge! ropte Ali. Han hadde fått på seg den gamle lusekofta til oldefar. Med flagget $i$ handa og et toskete smil, så han fullstendig norsk ut." (88) Det lekes med nasjonale heltefortellinger fra andre verdenskrig når Ali må flykte til fjells på ski under svært vanskelige forhold. Norsk krigshistorie setter dagens norske flyktningpolitikk i et lite flatterende lys. En skulle kanskje tro at flukten over fjellet ville gi en nordmann erfaringens fortrinn. Motbakkene er det imidlertid Marjaneh som behersker - og selv om hun avslører trikset med feller under skiene som "støttehjul for muslimer", utfordres Adrians forståelse av det å være norsk.

Selv om Marjaneh har en viktig rolle i avsløringen av Adrians fordommer, avdekkes det også et behov hos henne for å markere grenser for "vi" og "de andre". Basert på egne migrasjonserfaringer ser Marjaneh likheter mellom sin egen og Alis situasjon, men er 
likevel kjapp til å distansere seg og opprette et "vi" jordboere mot "de" fiendtlige utenomjordiske, med henvisning til filmene Klodenes kamp og Independence Day. Dermed kan Adrian påpeke Marjanehs fremmedfrykt - samtidig som han er i ferd med å erkjenne egne stereotypiske oppfatninger av romvesener med bakgrunn i blant annet Star Wars: "Jeg hadde i alle fall ikke trodd at romvesener skulle være nesten helt lik oss" (197). Det er verdt å merke seg at Adrian og Marjanehs holdninger til utenomjordisk liv er hentet fra vestlige sci-fi-filmer, hvilket viser fiksjoners potensielle påvirkningskraft. Den vestlige diskursen om "vi" og "de andre" har også overlevert kolonialt tankegods til Adrian som han ikke evner å gjennomskue. Til tross for at han erkjenner sine fordommer, fastholder Adrian Ali som sin eiendom: "Jeg tror jeg vil beholde han" (199).

\section{Globalisering - grenseløse fortellinger}

Norsk barnelitteratur er på ulike måter merket av globaliseringen. Erfaringer fra migrasjon og elektroniske medier utvider og utfordrer den norske horisonten, og signaler fra risikosamfunnet (Bech, 1997) krysser så vel aldersmessige som geografiske og kulturelle grenser. Disse grenseløse fortellinger kan skape angst - hos unge som gamle - men kan også gi ny innsikt. De siste tiårenes barn har i større grad enn tidligere måtte reflektere over problemstillinger som før var forbeholdt voksne øyne og ører. Neil Postman, amerikansk medieforsker, insisterte i 1982 på "the disappearance of childhood" og var svært betenkt over hvordan elektroniske medier fordrev barna fra det uskyldsrene barndomsparadiset. I så måte utfordrer globaliseringens "frie flyt" dikotomien mellom barn og voksne.

I Darlah spares det ikke på det alvorstunge skytset. Jeg tenker at apokalypsens sentrale plass har sammenheng medøkendeøkologisk bevissthet om klodens begrensede ressurser sett mot menneskenes svake globale konsekvensanalyse. Fascinasjonen for endetidsfortellingene synes som en kombinasjon av modernitetens angstfylte fremmedgjøringsfølelse og postmodernismens nihilistiske lek med den ultimate dødsdrift. Tar menneskets selvdestruktive og risikopregete adferd overhånd i det globaliserte risikosamfunns tidsalder? Romanens bruk av bilder og tekster fra virkeligheten tilslører grensene mellom fakta og fiksjon og bidrar til å gi boka et dokumentarisk preg som forsterker realismen i den dystopiske framtidsvisjonen - og dermed rettes et kritisk blikk mot vår tids samfunn.

Nettopp Darlahs form kan sees som et svar på globaliseringen og elektroniske mediers utfordring av boka som medium. Ikke bare 
vrimler det av intertekstuelle bånd til myter, spill, filmer - gjennom representasjoner av digitalt manipulerte fotografier og tekster fra mobiltelefon og pc søker bokmediet fornyelse gjennom å inkorporere nyere medier. Denne remedieringen finnes også i bokas kontekst, gjennom forbindelsen til The Lacktr Prpgnda Community ${ }^{1}$, samt gjennom bokas nettside ${ }^{2}$ med lyd- og filmklipp, lenker til NASA og interaktiv fanfiction. Bokmediets virkeområde utvides og inngår i et tverrmedialt felt. Jay David Bolter og Richard Grusin, amerikanske medieforskere, sier det slik: "The master narrative of our culture is no longer the story of God's relation to us or of our relation to nature, but of our relation to information technologies." $(1999,184)$ Darlah synes å kommunisere en ambivalens i forhold til teknologisk utvikling, idet innholdet skriver fram en teknologipessimisme mens formen i større grad utforsker digitale mediers muligheter.

\section{9/II - dystopi og ironi}

Terrorangrepet på tvillingtårnene er en hypermediert og globalisert hendelse. Selv om verden på ulike måter tok del i katastrofen, rammet terroren nasjonale symboler på amerikansk jord. 9/11 representerer et kritisk vendepunkt i amerikansk tenkning om "vi" og "de andre". Fiendebilder ble forsterket, og ifølge Jo Lampert viser amerikansk barnelitteratur om 9/11 en klar nasjonsbyggende trend. Til tross for at 9/11 har oppnådd ikonografisk status utover USAs grenser, så befinner norsk barndom og barnelitteratur seg et godt stykke fra Ground Zero. Global forbundethet gjenspeiles i mine norske eksempler, men protagonistene har en klar lokal og regional forankring fjernt fra New York. Som motiv brukes 9/11 både dystopisk og ironisk, der særlig det nasjonale aspektet rammes av ironi.

Darlah og En terrorist i senga går i hver sin retning hva gjelder globaliseringens muligheter og risikoer - noe som ikke minst kommer til syne i den motiviske behandlingen av 9/11. Som symbol har 9/11 flere og motstridende konnotasjoner avhengig av ens referansepunkt. Svært få har støttet den tyske komponisten Karlheinz Stockhausens tolkning av 9/11 som "the greatest work of art that exists for the whole Cosmos", et sitat fra en pressekonferanse i Hamburg 16.september 2001 som skapte betydelig kontrovers. En mer utbredt, om enn forenklet, tolkning av terrorangrepet kan oppsummeres i konflikten Jihad vs. McWorld. Motsetningsforholdet mellom antimodernisme/fundamentalisme og globalisering/kapitalisme er en konflikt som Benjamin Barber, amerikansk professor i politisk teori, 
beskrev flere år før 9/11. I Darlah brukes 9/11 i oppbyggingen av fryktscenarioet. Terroren i tvillingtårnene synes å dra i gang globaliseringens skjebnetid, med mennesket i en selvutslettende spiral som ender i apokalypsen. Den dystopiske ungdomsromanen opprettholder og forsterker dikotomien mellom "vi" og "de andre", der menneskehetens "vi" står mot "de fremmede" hvis menneskelige fasade skjuler iskalde drapsmaskiner fra ytre rom. Menneskene mister sin humanitet og blir en form, et medium for ren ondskap. Darlah kan også leses som en ironisering over nasjonale heltefortellinger. Der norske polarhelters naturbeherskelse bidro til oppbygging av en nasjonal identitet, blir romheltenes feilslåtte mestring av det uutforskede rom menneskehetens negative dannelseshistorie.

Også i En terrorist $i$ senga aksentueres det fremmedkulturelle med vesener fra verdensrommet. Identitetsmarkører som kjønn, alder, klær, hjem, skiferdigheter og flyinteresse problematiseres. Onde muslimer og gode nordmenn avsløres som fordomsfulle stereotypier - og blir dermed håndterbare størrelser. Oppdelingen i "vi" og "de andre" utfordres, og "vi-et" inkluderer ikke kun jorda og menneskeheten, men hele kosmos - i en feiring av vennskap og den avvæpnende latteren. Alis identitetsprosjekt blir også Adrians, Marjanehs og oldefars - selv om den koloniale arven synes å spøke i bakgrunnen. 9/11 brukes som motiv i en ironisk og humoristisk utlevering av fordommer mot "de andre", basert på religion, hudfarge eller nasjonalitet. Gjennom lek og humor dekonstrueres stereotypienes definisjonsmakt.

Kanskje barneromanen har sin mottaker i mente med den harmoniserende, hakkebakkeskogaktige normen "alle levende vesener skal være venner". Den dystopiske ungdomsromanen, som etterlater menneskeheten i karrige kår, er heller ikke uten håp. I et overordnet perspektiv framstår likevel En terrorist $i$ senga med et optimistisk kultursyn som får et pessimistisk motsvar i Darlah.

Biografisk information: Kjersti Lersbryggen Mørk, cand. philol., litteraturpedagog ved Norsk barnebokinstitutt. Kontakt: kjersti.lersbryggen.mork@ barnebokinstituttet.no

Illustrationerna vid artikelns början föreställer bildsekvenser ur (C) Johan Harstads Darlah - 172 timer på månen. Oslo: Cappelen Damm, 2008, samt omslaget till (C) Endre Lund Eriksens En terrorist i senga. Oslo: Aschehoug, 2008. 
${ }^{1}$ http:/ / lacktrprpgnda.blogspot.com/

${ }^{2}$ http:/ / www.stavanger-kulturhus.no/stavanger_bibliotek/barn_og_ ungdom/darlah

\section{Bibliografi}

Barber, Benjamin R. "Jihad vs. McWorld". The Atlantic monthly, 03. 1992.

Bech, Ulrich. Risikosamfundet: på vej mod en ny modernitet, København: Hans Reitzel, 1997.

Blatty, William Peter. The excorcist. Harper \& Row, 1971.

Bolter, Jay David og Richard Grusin. Remediation: understanding new media, Cambridge: MIT Press, 1999.

Bradford, Clare, Kerry Mallan, John Stephens and Robyn McCallum. New world orders in contemporary children's literature: utopian transformation, Hampshire/New York: Palgrave Macmillan, 2008.

Eriksen, Endre Lund. En terrorist $i$ senga, Oslo: Aschehoug, 2008.

Freud, Sigmund. The uncanny, Penguin Books, 2003. Essayet “Das Unheimliche" ble første gang utgitt i 1919.

Harstad, Johan. Darlah - 172 timer på månen, Oslo: Cappelen Damm, 2008.

Huddart, David. Homi K. Bhabha, London: Routledge, 2006.

Lampert, Jo. Children's fiction about 9/11: ethnic, heroic and national identities. New York: Routledge, 2010.

Postman, Neil. The disappearance of childhood. New York: Delacorte Press, 1982.

Reynolds, Kimberley. Radical children's literature: future visions and aesthetic: transformations in juvenile fiction. Hampshire/New York: Palgrave Macmillan, 2007.

Said, Edward W. Orientalism, London: Routledge \& Kegan Paul, 1978.

Tomlinson, John. Globalization and culture. Cambridge: Polity Press, 1999.

Ørjasæter, Kristin. "Barnelitteraturens bidrag til det nasjonale". I Årboka litteratur for barn og unge 2010. Red. Per Olav Kaldestad og Karin Beate Vold. Oslo: Samlaget, 2010.

Note: This article is being published simultaneously in Barnboken - tidskrift för barnlitteraturforskning/Journal of Children's Literature Research and Nordic ChildLit Aesthetics/Barnelitterært forskningstidsskrift 